\title{
Violación de derechos Humanos. el caso USA-México
}

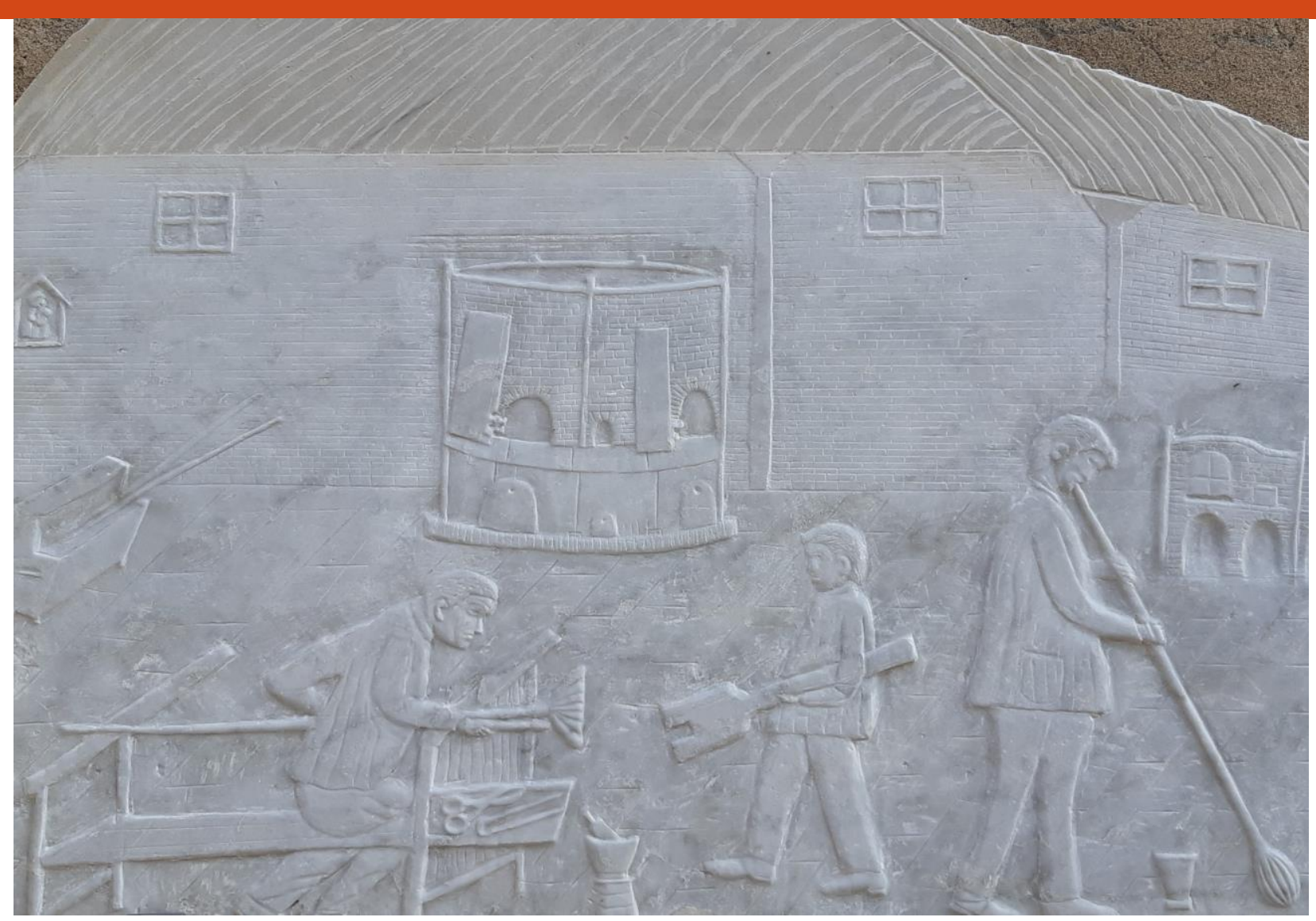

2021 ANNO VI NUMERO 12

di Alex Munguía Salazar DOI https://doi.org/10.54103/2531-6710/17359 


\title{
VIOLACIÓN DE DERECHOS HUMANOS. EL CASO USA- MÉXICO
}

\author{
di Alex Munguía Salazar
}

\section{HUMAN RIGHTS VIOLATIONS. THE USA-MEXICO CASE}

\section{Resumen}

El proceso migratorio entre México y Estados Unidos ha sido complejo y permanente a lo largo de la historia, Sin embargo, los Estados Unidos, en su condición de receptor de miles de trabajadores migrantes mexicanos cada año, han establecido su política migratoria, según las necesidades de su economía. Por momentos ha manifestado su aceptación a los flujos migratorios mexicanos, como lo fue con el "programa bracero" pero en otros como los actuales se muestra renuente con discursos oprobiosos como los enunciados por el actual presidente de los Estados Unidos Donald Trump, quien muestra su absoluto rechazo a tales flujos, mediante la implementación de regulaciones estrictas y atentatorias a cualquier principio de respeto a los derechos humanos de los trabajadores migrantes mexicanos.

Parole chiave: Derechos Humanos; Política migratoria; USA, Mexico

\section{Abstract}

The migration process between Mexico and the United States has been complex and permanent throughout history. However, the United States, as the recipient of thousands of Mexican migrant workers every year, has established its migration policy according to the needs of its economy. At times it has shown its acceptance of Mexican migratory flows, as was the case with the "bracero programme", (Munguía and Victoria:2017, p.43) but at other times, such as the current ones, it has shown its reluctance with opprobrious speeches such as those made by the current president of the United States, Donald Trump, who shows his absolute rejection of such flows, through the implementation of strict regulations that violate any principle of respect for the human rights of Mexican migrant workers.

Keywords: Human Rights; Migration policy; USA, Mexico

Autore: Alex Munguía Salazar, Doctor en Ciencias Políticas por la UNAM. Profesor-investigador tiempo completo Titular en la BUAP. amunguiasalazar@hotmail.com .

Articolo soggetto a revisione tra pari a doppio cieco

Articolo ricevuto il 30.1.20 approvato il 01/02/21 
Ninguna tesis podría ser más falsa que la aquí resumida como la tesis del entreguismo realista. La historia lo ha demostrado en la forma más explícita. No es que no debamos ser amigos de Estados Unidos, pero la mejor manera de ser buenos amigos de este país consiste precisamente en no ser obsecuentes, sino independientes. Así es como Estados Unidos respetará a la nación.

Jorge Castañeda, "Sobre la Política Exterior", La Jornada, 9 de octubre de 1988, p. 8

\section{Introducción}

Al hablar de política migratoria entre México y Estados Unidos, debemos hacer referencia al conjunto de decisiones estratégicas que, para alcanzar objetivos determinados, fundamentados en los principios generales y demás preceptos contenidos en la ley, se plasman en sus reglamentos, normas, programas y acciones concretas para atender el fenómeno migratorio de un país de manera integral, pues estamos hablando de un fenómeno casi inherente a la historia de estas dos naciones.

En lo que concierne a México al ser un país de origen, tránsito, destino y retorno de migrantes, el tema de la política migratoria ha sido desde siempre unos de los puntos esenciales a tratar en las administraciones gobernantes actuales, sin embargo, ello no quiere decir que el fenómeno haya sido asumido con responsabilidad. Estados Unidos, por su parte es uno de los países con mayor arribo de inmigrantes a su territorio, lo cual ha generado que en la actualidad, ese país intente frenar la migración, instrumentando una política migratoria excluyente y violatoria de cualquier principio de respeto a la dignidad humana. Impulsada por una plataforma política que sustenta su fuerza en el discurso antiinmigrante y específicamente antimexicano como lo es la administración actual del Republicano Donald Trump..

\section{La política migratoria después del 11 de septiembre del 2001}

La experiencia en los últimos años en la frontera entre Estados Unidos y México ha sido muy convulsa y difícil. Desde la perspectiva de Estados Unidos, se requería una frontera eficiente para el tráfico comercial, en el marco del TLCAN pero infranqueable para todo aquello no formalmente autorizado a hacerlo. Sin embargo, esta estrategia encerraba una gran contradicción, pues se pretendía, por un lado, el control de 
flujos migratorios que, por otra parte, se incentivaban por las implicaciones de la liberalización comercial que se impulsaban agresivamente. De hecho, el aumento en el intercambio comercial se dio de alrededor de 80 mil millones en 1993, a cerca de 250 mil millones en el año 2000.

Antes de que se diera la discusión binacional sobre el proceso de la migración, los atentados terroristas del 11 de septiembre, cancelaron las grandes expectativas que se habían creado al respecto. Este suceso, sin embargo, no canceló el interés por indagar sobre la gestión migratoria sólo que ahora en un contexto diferente, marcado por consideraciones de seguridad nacional y lucha antiterrorista.(Munguía:2016, p.55)

En este sentido, la forma en la que el gobierno de Estados Unidos abordó el tema de la seguridad fronteriza y el control migratorio no cambió con los eventos del 11 de septiembre de 2001; sin embargo, afectó la intensidad de las políticas: hubo una modificación en la visión y percepción del fenómeno, pero no en la estrategia para atacarlo y simplemente se intensificó, lo que ya se aplicaba. El incremento de controles ha sido controversial en lo que se refiere al movimiento de personas, por ejemplo, con la creación de registros electrónicos con información biométrica de cada persona que ingresa o sale del territorio. Lo anterior, se vio acompañado de políticas focalizadas en México, como la construcción de un muro en la frontera entre ambos países. (Hernández: 2008, p.209)

Para Estados Unidos, el atentado del 11 de septiembre representó, además de las irremplazables pérdidas humanas y monetarias ocasionadas a raíz del atentado que destruyó unos de los edificios más emblemáticos del país como lo fueron las Torres Gemelas, sobre todo, un descalabro para la seguridad nacional. Tradicionalmente la política de control migratorio y fronterizo de Estados Unidos ha sido solo coyuntural y responde a intereses y presiones políticas, más que a consideraciones objetivas que den respuesta al proceso migratorio y sus complejidades. Las medidas que ese país ha venido asumiendo en consecuencia después de los ataques del 11 de septiembre, se mantienen de esa manera y tienen efectos importantes en las relaciones internacionales de Estados Unidos con su vecino y uno de los principales socios comerciales, México. (Hernández: 2008, p. 209)

Actualmente, se han fortalecido los mecanismos de fiscalización de los movimientos migratorios, al mismo tiempo que se ha reforzado la lógica que atribuye a los inmigrantes y asilados un papel de potenciales amenazas a la seguridad del Estado y la sociedad. El resurgimiento de la soberanía nacional como factor 
crucial en el ámbito político, en virtud del clima de inseguridad actual, conduce nuevamente a un enfoque más restrictivo de los movimientos migratorios. (Alba y Leite: 2004, p. 4-20).

\section{La Ley Patriota y sus repercusiones en los derechos humanos}

De acuerdo con la política migratoria, restrictiva y determinada por los hechos del 11 de septiembre, bajo la idea de asimilar terrorismo con trabajador migrante, se estableció la Ley Patriota. Misma que fue diseñada por el fiscal John Ashcroft, impulsado por el Congreso y firmada como ley federal, por el entonces presidente Bush, en nombre de la seguridad nacional, el 26 de octubre del 2001, sólo seis semanas después del incidente del 11 de septiembre, y durante un periodo de gran confusión y miedo. Casi de manera simultánea, el Senado norteamericano aprobaba con 90 votos a favor y 9 en contra, la creación de una nueva Secretaría de Estado responsable de todas las tareas de seguridad interna bajo la jurisdicción federal. La nueva oficina del Ejecutivo, denominada Departamento de Seguridad Territorial, atrajo a 22 agencias federales, dispersas en otras secretarías, y agrupaba a 170 mil empleados gubernamentales, transformándose así, en el tercer empleador más grande del gobierno federal, detrás de los departamentos de Defensa y del de Asuntos de Veteranos. Con un presupuesto inicial de más de 35000 millones de dólares.(Munguía:2016, p.57)

Los ataques terroristas del 11 de septiembre causaron un reacomodo en las prioridades de seguridad de Estados Unidos, y para atenderlas, la administración Bush, decidió llevar a cabo una reestructuración administrativa integral y formular una nueva política de seguridad nacional. Después del 11 de septiembre, Bush solicitó y el Congreso aprobó la autorización para hacer uso de la fuerza contra cualquier país, organización o individuo que planee, autorice o cometa actos de terrorismo. Con fundamento en ella se invadió Afganistán e Irak.

En octubre del 2001, el Legislativo aprobó la Ley Patriota que, ampliaba considerablemente, las capacidades del gobierno para efectuar monitoreos electrónicos y espionaje telefónico, detener inmigrantes sospechosos y perseguir actos de lavado de dinero; un mes después, se implantó un plan que federalizaba la seguridad de los aeropuertos. En mayo del 2002, el gobierno tomó medidas para expandir las reservas de vacunas y para regular las actividades de los laboratorios que hacen investigación sobre microorganismos letales. Unos meses después, se autorizó a las líneas aéreas comerciales, cargar armas a bordo para la protección de las 
cabinas. A un año de los atentados, el entonces presidente de Estados Unidos George Bush formuló las nuevas directrices de seguridad nacional. La médula de esta doctrina era un internacionalismo militar activo para establecer un nuevo balance internacional de poder, "a favor de las libertades humanas y para derrotar la amenaza que representan los terroristas y los tiranos". Posteriormente, en octubre, el Congreso autorizó, una vez más al Presidente, hacer uso de las Fuerzas Armadas "para defender a Estados Unidos en contra de la amenaza que Irak representa" y para hacer cumplir en ese país "cualquier resolución relevante del Consejo de Seguridad de la ONU”. Para culminar, la administración logró en marzo del 2003, la creación del Departamento de Seguridad Interna.

Dentro de toda esta secuencia de instrumentos, acciones y posturas doctrinarias, los tres eslabones claves son la Ley Patriota, la Doctrina de Seguridad Nacional y el nuevo Departamento de Seguridad Interna, que representan la reorganización gubernamental más grande y ambiciosa desde que el entonces presidente Harry Truman, anunciara en los años cuarenta la fusión de los departamentos de Guerra y Marina, que dio origen al actual departamento de Defensa.

Las funciones del nuevo departamento están agrupadas en torno a un amplio rango de categorías que incluyen: la vigilancia fronteriza y la guardia costera, la seguridad en el transporte, la revisión aduanal, la inspección sanitaria, la prevención de emergencias, tales como ataques o accidentes nucleares e incidentes que involucren armas químicas y biológicas; el desarrollo de la ciencia y la aplicación de la tecnología a la seguridad, la protección de la infraestructura, incluidos los sistemas de telecomunicaciones; el desarrollo de los sistemas de información y servicios de inteligencia, y el servicio secreto. Anteriormente, estas funciones estaban en manos de los departamentos de Justicia, Transporte, Tesoro, Energía, Salud y Servicios Humanos, Comercio, Defensa, la Administración General de Servicios y el FBI. Por tanto, el reagrupamiento no sólo consistió en el traslado automático de funciones, personal y recursos, sino que fue una operación de transformación administrativa, para determinar lo que se iba a fusionar en la nueva Secretaría de Estado. La nueva agencia estableció mecanismos de coordinación e información con las dependencias que quedaron fuera de su jurisdicción administrativa, tales como la CIA, el FBI, la DEA y la Agencia de Seguridad Nacional. Esta reestructuración de la estrategia de seguridad nacional representó un hecho sin precedentes en la política norteamericana, dado que la nueva entidad federal cuenta con las facultades necesarias para conformarse, sin el monitoreo o interferencia del Congreso, violentando los 
derechos individuales y las libertades civiles. (Swarns:2003). Como sentimientos dominantes en el debate de seguridad, la opinión pública e incluso los órganos del Estado se mostraron más bien dispuestos a darle al ejecutivo amplias facultades, con la expectativa de que los actos terroristas puedan ser prevenidos y contrarrestados. Una demostración de ello, es el laudo emitido el 18 de noviembre 2002, por una corte federal especial de apelaciones que autoriza al Departamento de Justicia a llevar a cabo escuchas telefónicas con propósitos antiterroristas, por encima de las interpretaciones restrictivas que una corte menor había hecho a las disposiciones de la Ley Patriota. No obstante, es previsible que la creación del nuevo departamento y la aplicación de las disposiciones de la nueva doctrina de seguridad nacional e interna, enfrenten una mayor oposición pública en la medida que la eficacia de los nuevos mecanismos de seguridad sea puesta a prueba y, sus efectos sobre el régimen de libertades civiles, sean revalorados. Sin embargo, la fuerza reaccionaria de tales medidas sigue en pie y, además, se fortalece día a día.

Tras la aprobación de las medidas que pretenden "combatir" el terrorismo, como la nueva ley antiterrorista a la que se le denomina comúnmente "Ley Patriota" (USA Patriot Act). El entonces presidente Bush, firmó el polémico conjunto de medidas elaboradas por el Senado y la Cámara de Representantes que estuvieron vigentes, al menos durante catorce años, y que aumentó entre otros aspectos, las posibilidades de vigilancia en las comunicaciones vía Internet, por parte de las autoridades policiales en Estados Unidos. La puesta en práctica de esta ley fue contraria a los derechos humanos reconocidos por todos los instrumentos internacionales. Esta ley estableció severas restricciones a las diez primeras enmiendas de la Constitución estadounidense, como son. La V enmienda, sobre el debido proceso; ya que permite la detención indefinida y niega la comunicación con otros y con la inspección judicial. Puede llevar a la discriminación en contra de grupos étnicos. La I enmienda, sobre la libertad de expresión; debido a que contiene una definición muy amplia e imprecisa de "terrorismo doméstico", que puede ser usada en contra de los ciudadanos que ejercen su derecho a protestar. Extiende el acceso a las operaciones del programa de espionaje doméstico mejor conocido como Cointelpro, para controlar y vigilar a los grupos religiosos y políticos, sin una orden de cateo o prueba de delito. La IV enmienda, sobre el derecho a la privacidad; puesto que permite el acceso por parte de la FBI a los archivos del banco, al uso de la biblioteca, a la compra de libros y al correo electrónico, si se considera que existe sospecha de terrorismo. Asimismo, concede al Pentágono, acceso a los archivos de los alumnos de las escuelas secundarias. Permite al Ministro de Estado designar a cualquier grupo, que ha 
participado en algún acto de violencia, como "terrorista", dando lugar a que los grupos pacíficos sean designados como resultado de una acción por algún agente provocador. Permite inspeccionar los hogares sin previo aviso u orden de la corte.

Se autorizan detenciones en masa por tiempo indeterminado (sección 412); se permite que el Ministro de Justicia detenga a quienes no son ciudadanos, (incluyendo residentes permanentes que están legalmente) y que los puedan encarcelar por ser sospechosos, y les puedan negar el reingreso a los Estados Unidos, sólo por utilizar su derecho de participar en discursos protegidos por la primera enmienda de la constitución de los Estados Unidos (1st amendment). También, se puede utilizar esta ley por "Racial Profiling" o sea, para estigmatizar y discriminar a ciertos grupos étnicos, como los mexicanos. Remueve el sistema de comprobaciones y equilibrios "checks and balances" (secciones 214, 216); debilita, significativamente, el poder de las cortes judiciales de prevenir los abusos del FBI y otras autoridades judiciales, de espionaje ilegal de los teléfonos, el correo electrónico, y el Internet en casos de antiterrorismo o de cualquier investigación. Permite el espionaje (sección 213); aumenta la autoridad del gobierno con respeto al terrorismo e investigaciones corrientes para dirigir investigaciones secretas e indagar en asuntos personales. Estas investigaciones permiten que el FBI, use autorización judicial para entrar a una casa u oficina sin notificación alguna. Violenta el derecho a la intimidad (secciones 215, 508); conceden al FBI y a otras agencias de ley, acceso extenso a los documentos médicos, financieros, psicológicos y estudiantiles. Además, permite el acceso a los documentos y bibliotecas personales, así como también a compras hechas en librerías con la mínima vigilancia y criterios judiciales. Reduce los criterios necesarios para hacer investigaciones (sección 218); permite que las autoridades investiguen a personas en asuntos criminales, sin establecer motivo fundado, sino solo basada en una declaración, no comprobada. Nadamás tienen que enunciar que dicha investigación, está fundada en “objetivos de inteligencia.” Permite el espionaje doméstico (sección 901); la CIA y el FBI pueden espiar e investigar a toda organización interna. Los agentes pueden infiltrarse en recintos y agrupaciones religiosas, políticas y sociales, sin ninguna evidencia de un delito. Violenta el derecho a la libertad de expresión y participación (sección 803); incluye una definición de "terrorismo doméstico", demasiado extensa e imprecisa. La nueva definición es tan imprecisa que el gobierno pueda designar a organizaciones sociales legales, como como terroristas e imponerles espionaje, intercepciones de líneas 
telefónicas, amenazas, y además pueden ser castigadas criminalmente por su actuación. (Munguía: 2017, p. 66).

\section{La continuación de la Política Migratoria en la ley Arizona (Senate Bill 1070)}

El flujo migratorio, durante años ha ido en aumento, pero han surgido varios factores en los últimos años, que han ocasionado una disminución de hispanos hacia los Estados Unidos, como la crisis económica y financiera, la falta de una reforma migratoria, la deportación de indocumentados y las leyes anti inmigrantes y recientemente el discurso xenófobo y antimexicano del presidente norteamericano Donald Trump.

Desde 2008, se registró una disminución de mexicanos que emigraban hacia los Estados Unidos, debido a la crisis de bienes raíces que afectó a la industria de la construcción y otros sectores de la economía estadounidense, provocando el desempleo de millones de trabajadores indocumentados. A pesar de que el entonces presidente Barack Obama, había señalado que la reforma de la inmigración era tema prioritario para su gobierno, durante todo su periodo los legisladores republicanos y los demócratas en el Congreso, no lograron ponerse de acuerdo respecto a todos los millones de migrantes que residen sin autorización en Estados Unidos. Aunado a que la deportación de indocumentados se realizo de manera particularmente agresiva, como lo demuestran los 2.8 millones de deportados en los dos periodos de Obama. (Clemente: 2016) Si bien los Estados tienen la autoridad para establecer políticas de inmigración y para admitir o expulsar migrantes, deben de garantizar a los migrantes, un proceso de deportación digno y apegado a las normas internacionales.

Otro problema, que ha limitado el flujo migratorio, es el surgimiento y aprobación de leyes antiinmigrantes en Estados Unidos, como es la "Ley Arizona", que ha generado un clima de temor, angustia, miedo y desesperación, que ha llevando a las familias inmigrantes a abandonar Arizona y trasladarse a otros estados.

Arizona es un estado ubicado al suroeste de Estados Unidos y tiene una frontera internacional de 626 kilómetros de longitud, con los estados mexicanos de Sonora y Baja California. Por esta frontera internacional se generó una gran expansión de población en la década de 1990 en Arizona, creciendo en promedio $9.3 \%$ anual. Sin embargo, en la década siguiente este ritmo disminuyó a $3.5 \%$ anual, para llegar a un poco menos de 900000 personas inmigrantes en el estado, en el 2009. (Albo y Ordaz : 2011, p3) 
De la población nativa de Estados Unidos en 2009, en dicho estado $25 \%$ era de origen hispano. Dentro de estos últimos, los de origen mexicano representan la mayoría (cerca de 90 \%). La población extranjera de Arizona (cuadro 1) es también, en su mayoría, de origen mexicano (64\%). Sin embargo, dentro de los naturalizados, los de origen mexicano representan menos de la mitad (44\%). O visto de otra manera, las personas de origen mexicano en Arizona en 2009, suman aproximadamente 1.8 millones, de ellos los nacidos en el extranjero (México, principalmente), son aproximadamente 31\% y de los extranjeros, los que se encuentran no naturalizados, representan una proporción elevada de 76 \%. (Albo y Ordaz: 2011, p3)

Cuadro 1. Crecimiento poblacional en Arizona (miles de personas)

\begin{tabular}{|c|c|c|c|c|c|}
\hline & $\mathbf{1 9 9 0}$ & $\mathbf{2 0 0 0}$ & $\mathbf{2 0 0 9}$ & $\begin{array}{c}\text { Variación } \\
\text { promedio } \\
\text { anual 1990- } \\
\mathbf{2 0 0 0} \mathbf{( \% )}\end{array}$ & $\begin{array}{c}\text { Variación } \\
\text { promedio anual } \\
\mathbf{2 0 0 0 - 2 0 0 9} \mathbf{( \% )}\end{array}$ \\
\hline $\begin{array}{c}\text { Población nativa } \\
\text { de EEUU }\end{array}$ & $3,396.6$ & $4,478.4$ & $5,645.4$ & 2.2 & 2.6 \\
\hline $\begin{array}{c}\text { Nacidos en el } \\
\text { extranjero }\end{array}$ & 268.7 & 652.2 & 892.00 & 9.3 & 3.5 \\
\hline $\begin{array}{c}\text { Naturalizados } \\
\begin{array}{c}\text { No. De } \\
\text { ciudadanos }\end{array}\end{array} \quad 105.4$ & 194.9 & 306.1 & 6.3 & 2.1 \\
\hline estadounidenses & 163.3 & 457.3 & 585.9 & 10.8 & 2.8 \\
\hline Total & $3,6665.3$ & $5,130.6$ & $6,537.4$ & 3.4 & 2.7 \\
\hline
\end{tabular}

Fuente: BBVA Research con cifras de Gans (2008) y CPS, marzo 2009.

Cuadro 2. Población en Arizona según origen, 2009 (miles de personas)

\begin{tabular}{|c|c|c|c|c|c|}
\hline & Total & No hispano & Total & No mexicano & $\begin{array}{c}\text { De origen } \\
\text { mexicano }\end{array}$ \\
\hline $\begin{array}{c}\text { Población nativa } \\
\text { de EEUU }\end{array}$ & $5,645.4$ & $4,221.6$ & $1,423.8$ & 154.3 & $1,269.5$ \\
\hline $\begin{array}{c}\text { Nacidos en el } \\
\text { extranjero }\end{array}$ & 892.0 & 282.0 & 610.0 & 41.6 & 568.4 \\
\hline $\begin{array}{c}\text { Naturalizados } \\
\text { No Ciudadanos }\end{array}$ & 306.1 & 155.9 & 150.2 & 15.6 & 134.6 \\
\hline estadounidenses & 585.9 & 126.1 & 459.8 & 26.0 & $1,837.9$ \\
\hline Total & $6,537.4$ & $4,503.5$ & $2,033.8$ & 195.9 & $1,837.9$ \\
\hline
\end{tabular}

Fuente: BBVA Research con cifras de CPS, marzo 2009.

Cuadro 3. Participación de la población de Arizona en la población total de EE. UU. Según rubro, 2009 (\%).

Población nativa de EEUU

Nacidos en el extranjero

Naturalizados

No. Ciudadanos estadounidenses

De origen hispano

De origen mexicano

Nacidos en México

Fuente: BBVA Research con cifras de CPS, marzo 2009. 
En el estado de Arizona (cuadros 2 y 3 ) se encuentra poco más de $2 \%$ del total de la población de Estados Unidos. De los nacidos en el extranjero, se ubica ahí una proporción algo mayor: el 2.4 \%, pues alrededor de $6 \%$ de las personas de origen mexicano se concentra en este estado. (Albo y Ordaz: 2011, p4). En el ámbito laboral en Arizona (cuadro 4), las personas nativas de Estados Unidos tienden a concentrarse en las ocupaciones con mayor capacitación laboral. En 2009, el 37 \% se desempeña en actividades profesionales, de administración, negocios y actividades financieras. En forma complementaria, los migrantes en general destacan en servicios diversos (34.2\%), en actividades profesionales (13.6) y en transportación (10.9\%). Los migrantes mexicanos en Arizona, además de los servicios diversos (40.2\%) se concentran principalmente en la construcción y extracción (12.6 \%) y en la transportación (12.8 \%). El sector primario es importante como empleador (3.7\%), pero no es principal. Así, los migrantes, en general, no parecen competir por los puestos de trabajo con los trabajadores locales. Tienden a desempeñar actividades diferentes, y con ello a tener efectos económicos importantes en la economía de Arizona, como se analiza a continuación. (Albo y Ordaz: 2011,p 5)

Cuadro 4. Empleados en Arizona por tipo de ocupación, 2009 (\%)

\begin{tabular}{|c|c|c|c|}
\hline & & & Migrantes \\
\hline & Nativos & Total & Mexicanos \\
\hline $\begin{array}{c}\text { Administración, } \\
\text { negocios y actividades } \\
\text { financieras }\end{array}$ & 16.2 & 6.7 & 2.4 \\
\hline $\begin{array}{c}\text { Actividades } \\
\text { profesionales }\end{array}$ & 20.6 & 13.6 & 4.3 \\
\hline Servicios diversos & 16.5 & 34.2 & 40.2 \\
\hline $\begin{array}{c}\text { Ventas y ocupaciones } \\
\text { relacionadas }\end{array}$ & 13.9 & 8.8 & 6.3 \\
\hline $\begin{array}{c}\text { Ocupaciones de } \\
\text { administrativas y de } \\
\text { apoyo }\end{array}$ & 15.7 & 5.8 & 6.5 \\
\hline $\begin{array}{l}\text { Caza pesca y } \\
\text { reforestación }\end{array}$ & 0.1 & 2.4 & 3.7 \\
\hline $\begin{array}{l}\text { Construcción y } \\
\text { extracción }\end{array}$ & 4.8 & 8.4 & 12.6 \\
\hline $\begin{array}{l}\text { Instalación, } \\
\text { mantenimiento y } \\
\text { reparación }\end{array}$ & 3.9 & 3.8 & 3.9 \\
\hline $\begin{array}{l}\text { Ocupaciones de } \\
\text { reparación }\end{array}$ & 3.7 & 5.6 & 7.4 \\
\hline Transportación & 4.5 & 10.9 & 12.8 \\
\hline Total & 100.0 & 100.0 & 100.0 \\
\hline
\end{tabular}

Fuente: BBVA Research con cifras de CPS, marzo 2009.

Como ya vimos anteriormente, la importancia laboral de los mexicanos en Arizona y el alto número de migrantes que se establecen en el estado, es lo que motivó a la gobernadora Janice K. Brewer, a impulsar la 
Ley "SB1070", a pesar de saber que los migrantes hispanos en general contribuyen en la economía del estado, apoyan la creación de empleos, son consumidores y pagan impuestos.

La Ley de Inmigración de Arizona denominada "Safe neighborhoods: immigration and law enforcement", mejor conocida como iniciativa Senate Bill 1070, consiste en una modificación de varios capítulos del "Arizona Revised Statutes" (ars), codificación de las normas del Estado. La norma fue propuesta en el Senado de Arizona, por el Senador Richard Russell, y entró en vigor el 29 de julio de 2010, tras ser firmada por la gobernadora Janice K. Brewer. Durante la ceremonia de firma, la gobernadora republicana Brewer, sostenía que la SB1070, tenía como fin contribuir a la protección de los residentes contra "la delincuencia asociada con la inmigración ilegal" y se comprometió a rendir cuentas de que no sería "mal utilizada", es decir, que no violaría "los derechos de un individuo". Esta ley, agregó, "representa una nueva herramienta para que nuestro estado enfrente una crisis que no creamos y que el Gobierno federal ha rechazado arreglar". Uno de los aspectos más polémicos de la SB1070, es cuando la jueza federal Susan Bolton, suspendió parcialmente algunas disposiciones: (1) exigir a los funcionarios que comprueben el estatus migratorio de las personas detenidas, bajo la sospecha razonable de ser un inmigrante irregular; (2) criminalizar la falta de portación de documentos que prueben el estatus migratorio; (3) criminalizar a los inmigrantes la solicitud de empleo; y (4) detener a las personas inmigrantes sin orden judicial, cuando exista una causa probable para creer que la persona ha cometido un delito.

La ley de Arizona, prohíbe asimismo que las personas, en situación irregular, ofrezcan sus servicios como trabajadores empleados o independientes en la vía pública, que desempeñen empleo alguno, o que respondan a una oferta de empleo, siendo este tipo de delito inexistente en el marco federal. La Ley SB1070 también proscribe la práctica de recoger a inmigrantes en lugares públicos, donde éstos esperan para ser contactados u ofrecen sus servicios, con motivos de contratación laboral. La ley criminaliza, tanto el comportamiento de los ocupantes de los vehículos como el de los propios inmigrantes, que entran en ellos con propósitos laborales, vinculando aquí la lucha contra la inmigración ilegal con la seguridad vial, ya que dicha ofensa únicamente se aplica en el caso de que el vehículo bloquee o impida el flujo normal del tráfico. La introducción de este propósito, puede tener como intención vincular la disposición a una competencia 
eminentemente local o estatal, como lo es la regulación del tráfico, con el propósito de dificultar su anulación, por motivos relacionados con la distribución de competencias a nivel Federal.

La otra infracción penal es la consistente en transportar, albergar o alojar inmigrantes en situación irregular, en el caso de que la persona en cuestión sea consciente o negligentemente ignore dicha cualidad de irregular. No todo transporte de inmigrantes irregulares queda cubierto por esta norma, sino únicamente aquel que sea realizado con la intención de apoyar la presencia irregular. Por lo tanto, esta ley considera ilegal que los inmigrantes no autorizados soliciten trabajo en cualquier espacio público. Asimismo, es ilegal transportar, mover, ocultar, albergar o proteger a inmigrantes no autorizados o indocumentados, si la persona sabe que el inmigrante reside de manera ilegal en los Estados Unidos.

La ley obliga explícitamente a los agentes estatales y locales a investigar sobre el estatus de inmigración durante cualquier detención o arresto, sin una orden judicial, bajo sospecha de ser indocumentada. Así también, permite a los agentes detener a la persona para investigar sobre su estatus migratorio y comprobar que la persona cuente con documentos válidos. Es decir, esta ley obliga a las agencias policiacas a investigar el estatus de inmigración de cualquier persona durante el proceso de la ejecución de leyes estatales o locales, cuando existen ciertos indicadores, que puedan llamar la atención o levanten una "sospecha razonable", de que se encuentran ilegalmente en los Estados Unidos. La Ley SB 1070 hace que se considere un delito, no llevar los documentos apropiados de inmigración, y aplica una multa máxima de $\$ 100$ dólares y hasta 20 días en la cárcel por la primera violación, y hasta 30 días de cárcel, por una violación subsecuente. Pero el aspecto más preocupante es que la gran mayoría de los oficiales o agentes de la policía, no han sido capacitados para hacer cumplir la ley de inmigración y muchos ciudadanos estadounidenses y residentes legales podrían ser detenidos por error. Es importante señalar que hay estados que han seguido la iniciativa de Arizona, y han aprobado legislación similar como lo son los estados de Alabama, Georgia, Carolina del Sur y Utah (mapa 1). Aunque los tribunales federales han suspendido de manera temporal ciertas medidas, el juez del distrito del caso de Alabama, autorizó que se adoptaran algunas de las medidas extremas que aparecen en la ley de ese estado, la ley H.B. 56, a fin de que entren en vigor, incluyendo, una disposición que va más allá de la ley S.B. 1070 de Arizona, y que exige que se verifique la condición inmigratoria de los niños escolares, en el momento que se inscriben a la escuela. 


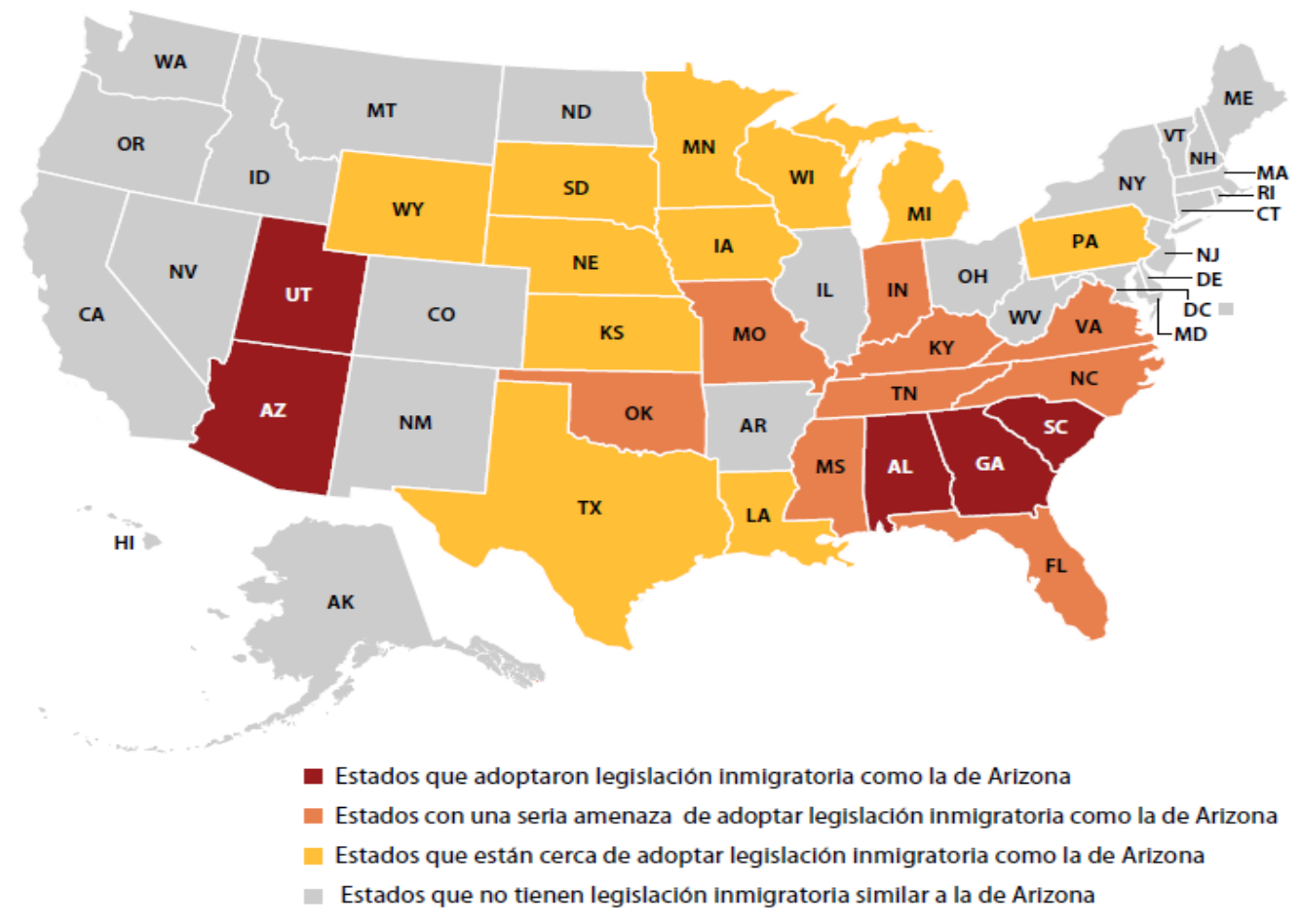

1Mapa 1. Estados de Norteamérica Que adoptaron una legislación Similar a la Ley Arizona

Fuente: http://www.americanprogress.org/wp-

content/uploads/espanol/articulos/2012/04/pdf/spanish_issue_brief_fitz_az_law.pdf

No se puede mejorar la calidad de vida de una población, si se utiliza la discriminación y la aversión, contra un numeroso grupo de la población que contribuye, a diario, al progreso económico de ese estado. Por lo tanto, dada la amplitud de las disposiciones de control migratorio contenidas en el SB 1070 y, el contexto en que se adoptó dicha ley, propició que se incurriera en violaciones significativas de derechos humanos. Por lo cual, Estados Unidos es responsable de estas violaciones de derechos humanos conforme a sus obligaciones internacionales.

El SB 1070, viola el derecho a la libertad personal en dos niveles diferentes. En primer lugar, como está establecido en los Organismos internacionales de derechos humanos, los Estados no pueden -imponer sanciones penales ni pueden detener a personas sobre la base de su condición de "indocumentadas". Así, si un Estado criminaliza la condición de migrante irregular, dicho Estado contraviene las normas de derechos humanos, de manera que la acción estatal será arbitraria y violatoria del derecho a la libertad personal.

En segundo lugar, las disposiciones específicas del SB 1070, prevén la detención automática y frecuentemente prolongada de los migrantes bajo una serie de circunstancias, como lo son investigar el 
estatus migratorio después de una retención policial; verificar y reportar el estatus migratorio con autoridades federales, en caso de arresto o condena, para que las autoridades de inmigración decidan ponerlo bajo su custodia.

En los (cuadros 5 y 6) se presentan las secciones válidas e inválidas que la jueza federal, Susan Bolton, suspendió temporalmente el 28 de julio del 2010, algunas secciones de la Ley Arizona aprobada el 23 de abril del 2010, la secciones suspendidas son: sección 2 (B), sección 3, sección 5 (C) y la sección 6(A)5.

Cuadro 5. Secciones suspendidas de la Ley Arizona

\begin{tabular}{|c|c|c|}
\hline \multicolumn{3}{|l|}{ LEY-SB1070 } \\
\hline \multicolumn{3}{|l|}{ Vigencia al 1 de marzo de 2012} \\
\hline Sección & Contenido breve & Vigencia \\
\hline $\begin{array}{l}\text { Sección 3. } \\
\text { Título 13, capítulo 15, Estatutos } \\
\text { Revisados de Arizona, Sección 13- } \\
1509 .\end{array}$ & $\begin{array}{l}\text { Es una violación a la ley no poseer y portar un } \\
\text { documento de registro de extranjero válido. }\end{array}$ & $\begin{array}{l}\text { Suspendida el } 28 \text { de julio de } \\
2010 \text {. }\end{array}$ \\
\hline $\begin{array}{l}\text { Sección } 5 . \\
\text { Título 13, capítulo 29, Estatutos } \\
\text { Revisados de Arizona, Sección 13- } \\
2928 \text { (C). }\end{array}$ & $\begin{array}{l}\text { Es ilegal que una persona solicite empleo en } \\
\text { un lugar público o realice una labor como } \\
\text { empleador o contratista. }\end{array}$ & $\begin{array}{l}\text { Suspendida el } 28 \text { de julio de } \\
2010 .\end{array}$ \\
\hline $\begin{array}{l}\text { Sección } 5 . \\
\text { Título 13, capítulo 29, Estatutos } \\
\text { Revisados de Arizona, Sección 13- } \\
2929 \text { (C ). }\end{array}$ & $\begin{array}{l}\text { Excepción para los trabajadores sociales, } \\
\text { choferes de ambulancia y paramédicos que } \\
\text { esté transportando a un extranjero dentro del } \\
\text { estado. }\end{array}$ & $\begin{array}{l}\text { Suspendida el } 28 \text { de julio de } \\
2010 .\end{array}$ \\
\hline $\begin{array}{l}\text { Sección 6, Sección 13-3883, } \\
\text { Sección (A) } 5 .\end{array}$ & $\begin{array}{l}\text { Arresto sin una orden judicial por un agente } \\
\text { policiaco, de personas que hayan cometido un } \\
\text { delito público que las hace sujetas a una } \\
\text { probable deportación. }\end{array}$ & $\begin{array}{l}\text { Suspendida el } 28 \text { de julio de } \\
2010 .\end{array}$ \\
\hline $\begin{array}{l}\text { Sección } 5 . \\
\text { Título 13, capítulo 29, Estatutos } \\
\text { Revisados de Arizona, Sección 13- } \\
2928 \text { (A). }\end{array}$ & $\begin{array}{l}\text { Es ilegal contratar y subir pasajeros a un } \\
\text { vehículo en una calle o carretera, que impida } \\
\text { el movimiento normal de tráfico. }\end{array}$ & $\begin{array}{l}\text { Suspendida el } 29 \text { de febrero de } \\
2012 .\end{array}$ \\
\hline $\begin{array}{l}\text { Sección } 5 . \\
\text { Título 13, capítulo 29, Estatutos } \\
\text { Revisados de Arizona, Sección 13- } \\
2928 \text { (B). }\end{array}$ & $\begin{array}{l}\text { Es ilegal que cualquier persona suba a un } \\
\text { vehículo detenido en una calle o carretera, } \\
\text { para ser contratado y transportado a otro } \\
\text { lugar diferente, si el vehículo impide el } \\
\text { movimiento normal de tráfico. }\end{array}$ & $\begin{array}{l}\text { Suspendida el } 29 \text { de febrero de } \\
2012 .\end{array}$ \\
\hline
\end{tabular}

Fuente: SRE. Disponible en:

http:/ / consulmex.sre.gob.mx/sb1070/index.php?option $=$ com_content $\& v i e w=$ article $\&$ id $=48 \& I t e m i d=81$

Cuadro 6. Secciones vigentes de la Ley Arizona

\begin{tabular}{|l|l|l|}
\hline LEY-SB1070 \\
\hline Vigencia al 1 de marzo de 2012. \\
\hline Sección & Contenido breve & Vigencia \\
\hline Sección 1. & Propósito de la ley & Vigente \\
\hline Sección 2. & $\begin{array}{l}\text { Cooperación y asistencia en la aplicación de leyes } \\
\text { de inmigración: Indemnización. }\end{array}$ & Vigentes \\
\hline
\end{tabular}




\begin{tabular}{|c|c|c|}
\hline \multicolumn{3}{|l|}{ LEY-SB1070 } \\
\hline \multicolumn{3}{|l|}{ Vigencia al 1 de marzo de 2012.} \\
\hline Sección & Contenido breve & Vigencia \\
\hline $\begin{array}{l}\text { Se enmienda el Título 11, } \\
\text { capítulo 7, ARS 11-1051, } \\
\text { Sección (A) a la (L). }\end{array}$ & & \\
\hline $\begin{array}{l}\text { Sección } 4 . \\
\text { Sección 13-2319, Estatutos } \\
\text { Revisados de Arizona. }\end{array}$ & Contrabando; clasificación; definiciones. & Vigente \\
\hline $\begin{array}{l}\text { Sección } 5 . \\
\text { Título 13, capítulo } 29, \\
\text { Estatutos Revisados de } \\
\text { Arizona, Sección 13-2928 (D) a } \\
\text { la (G). }\end{array}$ & $\begin{array}{l}\text { Detenerse en un vehículo para contratar o } \\
\text { recoger a pasajeros en su sitio de trabajo: } \\
\text { aplicación, oferta de empleo y clasificación ilícita, } \\
\text { definición. }\end{array}$ & Vigentes \\
\hline $\begin{array}{l}\text { Sección } 5 . \\
\text { Título 13, capítulo 29, } \\
\text { Estatutos Revisados de } \\
\text { Arizona, Sección 13-2929 (A) y } \\
\text { (B). }\end{array}$ & $\begin{array}{l}\text { Transportar, trasladar, ocultar, acoger o proteger } \\
\text { a personas indocumentadas será causa del } \\
\text { embargo del vehículo; excepciones; clasificación. }\end{array}$ & Vigentes \\
\hline $\begin{array}{l}\text { Sección 6. } \\
\text { Estatutos Revisados de } \\
\text { Arizona Sección 13-3883, } \\
\text { Sección (A) 1. a, Sección (A) 4. }\end{array}$ & $\begin{array}{l}\text { Arresto sin orden judicial por un agente } \\
\text { policiaco. }\end{array}$ & Vigentes \\
\hline $\begin{array}{l}\text { Sección } 6 . \\
\text { Estatutos Revisados de } \\
\text { Arizona, Sección 13-3883, } \\
\text { Sección (B). }\end{array}$ & $\begin{array}{l}\text { Arresto sin orden judicial por un agente } \\
\text { policiaco. }\end{array}$ & Vigente \\
\hline $\begin{array}{l}\text { Sección } 7 . \\
\text { Estatutos Revisados de } \\
\text { Arizona } \\
\text { Sección 23-212, Sección (A) a } \\
\text { la (L). }\end{array}$ & $\begin{array}{l}\text { Emplear a un extranjero no autorizado, a } \\
\text { sabiendas de su estatus: prohibición: quejas falsas } \\
\text { y frívolas: violación: clasificación, suspensión de } \\
\text { licencia y revocación, defensa afirmativa. }\end{array}$ & Vigentes \\
\hline $\begin{array}{l}\text { Sección } 8 . \\
\text { Estatutos Revisados de } \\
\text { Arizona Sección 23-212.01, } \\
\text { Sección (A) a la (L). }\end{array}$ & $\begin{array}{l}\text { Emplear con conocimiento de causa a un } \\
\text { extranjero no autorizado: prohibición: demandas } \\
\text { falsas y/o frívolas: violación: clasificación, } \\
\text { suspensión de licencia y revocación, defensa } \\
\text { afirmativa. }\end{array}$ & Vigentes \\
\hline $\begin{array}{l}\text { Sección } 9 . \\
\text { Estatutos Revisados de } \\
\text { Arizona Sección 23-214, } \\
\text { Sección (A) a la (C). }\end{array}$ & $\begin{array}{l}\text { Verificación de elegibilidad en el trabajo: } \\
\text { programa E-verify. Incentivos del desarrollo } \\
\text { económico: lista de empleadores registrados. }\end{array}$ & Vigentes \\
\hline $\begin{array}{l}\text { Sección } 10 . \\
\text { Sección 28-3511, Sección (A) a } \\
\text { la (F). }\end{array}$ & $\begin{array}{l}\text { Remoción e inmovilización o incautación de } \\
\text { vehículos }\end{array}$ & Vigentes \\
\hline $\begin{array}{l}\text { Sección. } 11 . \\
\text { Título 41, capítulo 12, artículo } \\
\text { 12, Estatutos Revisados de } \\
\text { Arizona, Sección 41-1724. }\end{array}$ & $\begin{array}{l}\text { Fondo de reforzamiento del equipo de } \\
\text { inteligencia contra pandillas e inmigración }\end{array}$ & Vigente \\
\hline $\begin{array}{l}\text { Sección } 12 . \\
\text { Divisibilidad, implementación } \\
\text { y construcción. }\end{array}$ & $\begin{array}{l}\text { La pérdida de vigencia de alguna sección de esta } \\
\text { ley no afecta a las otras secciones y respetando los } \\
\text { derechos civiles de las personas en Estados } \\
\text { Unidos. }\end{array}$ & Vigente \\
\hline $\begin{array}{l}\text { Sección } 13 . \\
\text { Título corto }\end{array}$ & $\begin{array}{l}\text { "Acto de Apoyar Nuestras Autoridades de } \\
\text { Cumplimiento de la Ley y Vecindarios Seguros" }\end{array}$ & Vigente \\
\hline
\end{tabular}

Fuente: SRE. Disponible en:

http:/ / consulmex.sre.gob.mx/sb1070/index.php?option $=$ com_content $\& v i e w=$ article $\& i d=48 \& I t e m i d=81$ 


\section{La acción ejecutiva del Gobierno de Barack Obama DACA y DAPA}

Uno de los programas que intentaron remediar la indefinición del estatus migratorio indocumentado fue el anunciado el 15 de junio del 2012 por el entonces presidente Barack Obama, quien señaló que el Departamento de Seguridad Interior (DHS por sus siglas en inglés) no deportaría a ciertos jóvenes indocumentados que llegaron a los Estados Unidos siendo niños. Por medio de una directiva de la secretaria del DHS, a estos jóvenes se les podía otorgar un permiso temporal para permanecer en los EE.UU., llamado "acción diferida". La administración de Barack Obama le llamó a este proceso "la acción diferida para los llegados en la infancia," o Deferred Action for Childhood Arrivals (DACA por sus siglas en inglés).

La acción diferida concedida bajo DACA era válida por dos años y podía ser renovada por un periodo adicional de dos años. Sin embargo otra acción ejecutiva efectuada por el entonces presidente Barack Obama en noviembre de 2014 aumentaba el plazo a tres años, con el respectivo aumento al periodo de renovación a 3 años; lo cual propició que 26 estados entablaran una demanda cuestionando su legalidad. Un juez federal en Texas bloqueó su implementación en febrero de 2015, por lo cual nunca entró en vigor la reforma a DACA. (Castillo: 2017)

Actualmente, el Servicio de Ciudadanía e Inmigración de Estados Unidos (USCIS por sus siglas en inglés) sigue aceptando solicitudes de renovación para personas que previamente recibieron DACA y ahora desean renovarla y también de personas que solicitan DACA por primera vez. Todos aquellos que envíen ya sea una solicitud de DACA inicial o una solicitud de renovación de DACA deben utilizar la versión final del formulario de renovación de solicitud DACA (Formulario I-821D). Es importante señalar que las personas que reciban la acción diferida podrán solicitar y obtener una autorización de empleo.

Sin embargo, es importante señalar que la acción diferida es un trámite administrativo que previene una deportación y que ha existido desde hace mucho tiempo. Por esta vía, el Departamento de Seguridad Interior permite que un ciudadano no estadounidense permanezca en los EE.UU. temporalmente como "legalmente presente" por el tiempo que su acción diferida esté en efecto. La persona puede solicitar un documento de 
autorización de empleo ("permiso de trabajo") para el periodo durante el cual esté bajo la acción diferida. Pero es importante enfatizar que el otorgamiento de DACA es discrecional, y que sólo es una solución temporal y no ofrece un camino al estatus de residente legal permanente o a la ciudadanía de los EE.UU.

El programa DACA establece los siguientes requisitos:

- Haber nacido en o después del 16 de junio de 1981.

- Haber llegado a los Estados Unidos antes de la edad de dieciséis años.

- Haber vivido continuamente en los Estados Unidos desde el 15 de junio del 2007.

- Haber estado presente en los Estados Unidos el 15 de junio del 2012 y todos los días desde el 15 de agosto de 2012.

- No haber tenido un estatus migratorio autorizado. Para calificar, la persona debió de haber entrado a los Estados Unidos sin autorización antes del 15 de junio del 2012, o si entró con autorización, su estatus de inmigración debe de haber vencido antes del 15 de junio del 2012 y no debe tener un estatus legal de inmigración a la hora de aplicar.

- Tener por lo menos 15 años de edad. Si se está actualmente en proceso de deportación, o se tiene una orden de salida voluntaria pendiente, o se tiene una orden de deportación y no se encuentra bajo custodia de inmigración, se puede solicitar la acción diferida, incluso si todavía no se tiene 15 años de edad.

- Haberse graduado u obtenido un certificado de que terminó la escuela secundaria (High School), haber obtenido un Certificado de Educación General (GED), ser un veterano con descargo honorable de la Guardia Costera o de las fuerzas armadas de los Estados Unidos o "estar inscrito en la escuela" en el momento de presentar su petición de acción diferida.

- No haber sido condenado por un delito grave (felonía). Una felonía es un delito federal, estatal, o local que pueda ser penado con cárcel por un año o más.

- No haber sido condenado por un delito menor ("misdemeanor offense") "significativo" o tres delitos menores.

- No representar una amenaza para la seguridad nacional o seguridad pública. (Aunque el 
Departamento de Seguridad Interna no ha definido claramente estos términos, pero ha indicado que incluyen participación en una pandilla, participación en actividades criminales, o participación en actividades que amenazan a los Estados Unidos)

- Pasar una verificación de seguridad que podría incluir una revisión de antecedentes penales.

Es importante señalar que junto con el formulario I-821D, se debe completar y enviar el formulario I765 y el I-765WS solicitando un permiso de trabajo, pero se debe demostrar una necesidad económica para obtener el permiso de trabajo. (USCIS: 2017) Las revisiones de USCIS incluyen la verificación de la información biográfica y biométrica en las bases de datos del gobierno federal.

Para calificar en el programa DACA se deben reunir documentos tales como registros financieros (contratos de renta, comprobantes de servicio de teléfono, de cuentas de tarjetas de crédito, etc.), registros médicos, registros de la escuela (diplomas, reportes de calificaciones, expedientes académicos), registro de empleos, y registro del servicio militar.

Para comprobar que se ha vivido en los EE.UU. continuamente desde el 15 de junio del 2007, se deben de proporcionar documentos que comprueben su presencia en los Estados Unidos durante ese periodo. Como regla general, se debe entregar un documento por cada periodo de 12 meses desde el 15 de junio del 2007. Si no se tienen los documentos necesarios para comprobar su presencia en el país durante una parte significativa del periodo entre junio del 2007 y el momento actual, se deben entregar declaraciones juradas de por lo menos dos personas que tengan conocimiento de su estadía durante ese periodo.

Si ha sido arrestado alguna vez, se debe solicitar una copia de sus antecedentes penales de su estado o de la Oficina Federal de Investigaciones (FBI por sus siglas en inglés). También se debe solicitar de cada tribunal, en el que ha tenido un delito, una carta explicando lo que el juez decidió finalmente en cada caso. Esta carta se conoce como una "carta de disposición” o "certificado de disposición” (“disposition letter" o “certificate of disposition”).

Todos los documentos que se envíen a USCIS que no sean en ingles se tienen que traducir al inglés. Al final de cada documento traducido de otro idioma al inglés, se debe presentar una declaración fechada y firmada certificando que se está capacitado para traducir de ese idioma al inglés. Sólo se debe certificar que 
se es competente para hacer la traducción, puesto que las traducciones no tienen que ser notariadas.

Es importante señalar que sólo se debe proporcionar un número de seguro social si fue emitido debidamente por la Administración del Seguro Social (Social Security Administration). No se debe incluir un ITIN (Individual Taxpayer Identification Number, o Número de identificación personal del contribuyente), o cualquier otro número de seguro social que se hubiera utilizado, en sus solicitudes de acción diferida y de autorización de empleo.

Además, es necesario el señalar que un delito menor es un delito para el cual la pena máxima de prisión es de un año o menos, pero más de cinco días. Un sólo delito menor "significativo" lo hace inelegible para la acción diferida. El DHS considera lo siguiente como delitos menores "significativos":

- Una ofensa de violencia doméstica, abuso o explotación sexual, robo (“burglary”), posesión o uso ilegal de un arma de fuego, distribución o tráfico de drogas, manejar bajo la influencia del alcohol o drogas (estos delitos se consideran delitos menores "significativos", independientemente de la duración de la pena que se impone).

- Para las ofensas no incluidas en esta lista, un delito menor "significativo" es aquel por el cual hubo una sentencia de más de 90 días en la cárcel. Esto no incluye una sentencia suspendida.

Los delitos que se consideran "tres o más delitos menores" "misdemeanor offenses", son:

- Cualquier delito menor (que no se considere un delito menor "significativo") por el cual se impone una sentencia de por lo menos un día en custodia es considerado un delito menor.

- No se cuentan ofensas menores de tráfico, a menos que sean relacionadas con drogas o alcohol.

- No se cuentan ofensas menores relacionadas con leyes de inmigración estatales, como las leyes en Arizona, Alabama, y otros estados que han creado leyes criminalizando las actividades cotidianas de personas indocumentadas. Estos crímenes no cuentan como felonías o delitos menores.

- DHS analizará todos los factores y las circunstancias de cada caso para determinar si una persona que ha cometido algún delito califica para la acción diferida.

Es importante señalar que la acción diferida de 2012 de DACA es otorgada por un periodo de dos años 
y se podrá solicitar la renovación de su DACA y permiso de trabajo por un periodo adicional de dos años. (NILC: 2017)

Sin embargo es necesario señalar que los cambios en la acción ejecutiva del presidente Obama de 2014, la cual nunca entró en vigor, eliminaba la restricción de 31 años que impone para solicitar DACA, y ampliaba el plazo de vigencia de 2 a 3 años, con el respectivo permiso de trabajo.

El USCIS implementaría los nuevos cambios para el mes de febrero del 2015, sin embargo por resolución de una corte federal fue suspendida su aplicación en esa misma fecha, ya que se había estipulado que entraría en vigor 90 días después del anuncio del Presidente el 20 de noviembre de 2014 . En este sentido, una de las acciones propuestas por Obama en esa acción ejecutiva era la creación el programa de Acción Diferida para Responsabilidad de los Padres o Deferred Action for Parental Accountability (DAPA, por sus siglas en inglés), la cual señalaba que si se tiene un hijo nacido en Estados Unidos antes del 21 de noviembre del 2014 y no se es prioridad para la deportación, podría optar por este programa. Los padres debían ser inmigrantes indocumentados y debían cumplir con los siguientes requisitos para presentar una petición de DAPA al Servicio de Ciudadanía e Inmigración de Estados Unidos (USCIS) y calificar al programa:

Ser un padre o madre de un ciudadano o residente permanente de los EE.UU. que nació en o antes del 20 de noviembre de 2014 (fecha del anuncio presidencial); Haber vivido continuamente en los Estados Unidos desde antes del 1 de enero de 2010; Estar físicamente presente en los Estados Unidos el 20 de noviembre de 2014, y al momento de presentar la petición de DAPA ante el USCIS; No tener estatus legal el 20 de noviembre de 2014: No ser una prioridad para la deportación, según el Memorándum de Política de Captura, Detención y Remoción de Inmigrantes Indocumentados. (DHS: 2014) y No tener otros factores que lo descalifiquen ante la discrecionalidad del USCIS.

Es importante señalar que el gobierno federal considera como prioridad de deportación a personas que son asumidas como "una amenaza" para la seguridad nacional y seguridad pública, que han cometido ciertas clases de crímenes o tienen una orden de deportación final emitida después del 1 de enero del 2014. El USCIS implementaría el programa DAPA después de 180 días (6 meses) a partir de su anuncio el 20 de noviembre de 2014, lo cual nunca pasó. 
Hay que enfatizar que las acciones ejecutivas de Obama son temporales y no protegerían a todos los indocumentados que están viviendo en los Estados Unidos, incluyendo a personas que posiblemente han estado viviendo en el país durante décadas, como lo podemos constatar en el caso de la migración mexicana. La única manera que se pueda arreglar el sistema migratorio es por medio de la aprobación de una reforma migratoria integral, y esto aún está en manos del Congreso de los Estados Unidos. (White House: 2014)

\section{Conclusiones}

El proceso migratorio entre México y Estados Unidos ha sido complejo y permanente desde una perspectiva histórica y en la actualidad. Y dadas las condiciones económicas, sociales, culturales y geográficas específicas de ambos Estados, es y será imparable. Los Estados Unidos, en su condición de receptor de miles de trabajadores migrantes mexicanos cada año, han establecido su política migratoria, según las necesidades de su economía. Por momentos ha manifestado su aceptación a los flujos migratorios mexicanos, como lo fue durante el periodo de posguerra con el "programa bracero", como en otros, muestra su absoluto rechazo a tales flujos, mediante la implementación de regulaciones como la Ley de Reforma de la Inmigración Ilegal y de Responsabilidad del Inmigrante; la Ley Antiterrorismo y Pena de Muerte Efectiva; y la Ley de Conciliación de la Responsabilidad Personal y las Oportunidades de Trabajo de 1996, así como los intentos de legislaciones excluyentes en los Estados, como la Ley SB1070 del estado de Arizona, que entre otras acciones, aumentaron los controles fronterizos, ordenan nuevos programas para verificación de empleos, establece la elegibilidad para los programas de prestación de servicios públicos, considera inadmisibles por periodos de tres a diez años, a aquellos que sean detectados como migrantes previos no autorizados, estableciendo penas más severas para asuntos migratorios, como la deportación sin el debido proceso; todo esto con un respaldo a nivel federal de una ley que ha sido oprobiosa y contraria a cualquier principio de respeto como lo es la mal conocida Ley Patriota que a pesar de ya no estar de manera formal en vigencia, sigue ahora como USA Freedom Act que establece un escenario de agresión a principios democráticos y de vigencia a derechos humanos.

\section{Bibliografia}


Alba, Francisco y Paula Leite, (2004) "Politicas migratorias después del 11 de septiembre: los casos del TLCAN y la UE”, Migración y Desarrollo, núm. 2, abril, México, Red Internacional de Migración y Desarrollo. Disponible en http://www.redalyc.org/pdf/660/66000202.pdf

Albo, Adolfo y Ordaz, Juan Luis, (2011), “Migración y remesas. ¿La reducción de las remesas contribuyó al aumento de la pobreza?", Observatorio Económico de México, Grupo BBVA, Servicio de Estudios Económicos. Disponible en:

http://www.bbvaresearch.com/KETD/fbin/mult/110926 MigracionMexico 30 tcm346269927.pde?ts $=2692011$.

Castillo Nelson A. (2017) "Gobierno de Trump revoca DAPA, mantiene DACA original”, Inmigración Hoy. https://inmigracionhoy.com/tag/dapa/

Clemente, Anabel (2016), “Con 2.8 millones, Obama es el que más ha deportado indocumentados”, El

Financiero. http://www.elfinanciero.com.mx/nacional/con-millones-obama-es-el-que-mas-ha-deportado-

\section{indocumentados.html}

Hernandez Joseph, Daniel, (2008) "Política Migratoria y de control fronterizo de Estados Unidos hacia México y Centroamerica", Revista Enfoques, año VI, núm. 8, Primer Semestre. Disponible en: http:/ $/$ www.redalyc.org/articulo.oa?id $=96060811$

The White House (2014) Acción ejecutiva de responsabilidad por la inmigración. Disponible en: https://www.whitehouse.gov/the-press-office/2014/11/20/hoja-informativa-acci-n-ejecutiva-de-

\section{$\underline{\text { responsabilidad-por-la-inmigraci-n }}$}

DHS Department of Homeland Security, (2014), Memorandum, Policies for the Apprehension, Detention and Removal of Undocumented Immigrants. Disponible en: http://www.dhs.gov/sites/default/files/publications/14_1120_memo_prosecutorial_discretion.pdf

Munguía Salazar, Alex (2016) Las políticas migratorias y los planes de militarización regional, en Munguía Salazar, Alex et al, Derecho Internacional, Terrorismo y Política Humanitaria Global, Plaza y Valdez, México. 
Munguía Salazar, Alex y Victoria de la Rosa Silvano (2017) La migración mexicana a los Estados Unidos, durante el Programa Bracero del siglo XX, en Munguía Salazar, Alex et al, Temas Contemporáneos de

$\stackrel{\circ}{\stackrel{2}{\infty}}$

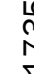
Derecho Internacional, Plaza y Valdez, México.

Swarns, Rachel L., (2003) "Illegal Aliens Can Be Held Indefinitely, Ashcroft Says", New York Times, http://www.nytimes.com/2003/04/26/international/worldspecial/26IMMI.html

NILC National Immigration Law Center, 2017. www.nilc.org/renovardaca.html

USCIS U.S. Citizenship and Immigration Services, (2017) web oficial del Departamento de Seguridad Nacional. www.uscis.gov/es/formularios/i-765.

Sitografia

"Permiten a Bush ocultar detenidos", (2003), Periódico Reforma, México, (http://www.reforma.com/ed_impresa/default.asp)." 